Ömür Akyazı

Karadeniz Teknik Universty, oakyazi@ktu.edu.tr, Trabzon-Turkey

\begin{tabular}{l|l|l}
\hline DOI & \multicolumn{2}{|c}{$\mathrm{http}: / / \mathrm{dx} . \mathrm{doi}$. org/10.12739/NWSA.2018.13.1.2A0134 } \\
\hline ORCID ID & $0000-0001-6266-2323$ \\
\hline
\end{tabular}

\title{
GA-BASED FUZZY LOGIC CONTROLLER WITH BOOSTER TYPE DC-DC CONVERTER
}

\section{ABSTRACT}

In this study, a booster-type DC-DC converter is designed by Matlab/Simulink Environment and an output voltage control has been analyzed for different load conditions. The designed DC-DC converter is controlled for different scenarios such as variable input-constant output voltage and constant input-variable output voltage references. The converter controller performance is observed with using classical Proportional+Integral (PI) controller and Fuzzy Logic Controller (FLC). On the other hand, the controller parameters are determined by employing Genetic Algorithm (GA) according to Integral of the Time weighted Absolute Error (ITAE) to improve the controller performance. Thus, more efficient and intelligent controllers are obtained for the DC-DC converter system. The system simulation is realized by the Matlab/Simulink and results are compared with each other.

Keywords: Booster Type DC-DC Converter, PI, FLC, ITAE, Genetic Algorithm

\section{INTRODUCTION}

Today, the usage of switched DC-DC converters has become widespread in industrial applications in parallel with the technological developments. The control of these systems is quite difficult since the DC-DC converters have non-linear and time-varying features. The control of system directly effects on the efficiency of the DC-DC converters [1 and 2]. Most of the researches, who are interested in the DC-DC converter technologies, have focused on the better method of switching to be revealed. Therefore, the control methods using for controlling DC-DC converters have a substantial role in determination of the converter performance. In generally, the DC-DC converter topologies prefer to control the output voltage of the converter by using Pulse Width Modulation (PWM) technique [3]. In the literature, there are many different types of DC-DC converter topologies such as buck, boost, buck-boost, cuk and full bridge and etc. the DC-DC converter topologies are mainly based on the buck and boost converters [3 and 5]. In this study, a DC-DC boost converter has been designed at the Matlab/Simulink. The system is controlled to convert the variable DC input voltage applied to its input to a desired constant output voltage or to obtain the desired variable DC voltage from its output by applying the fixed DC voltage to the system input. Proportional + integral (PI) and Fuzzy Logic Controller (FLC) techniques are employed for the system control and the controller performances are compared with each other. Moreover, in order to improve the performance of the controllers, some parameters pertaining to the controller are determined using the Genetic Algorithm (GA) according to integral of the time weighted absolute error (ITAE).

How to Cite:

Akyazı, Ö., (2018). Ga-Based Fuzzy Logic Controller with Booster Type Dc-Dc Converter, Technological Applied Sciences (NWSATAS), $13(1): 34-43$,

DOI : 10.12739/NWSA.2018.13.1.2A0134. 
Thus, a more efficient control is provided for the system. The general block diagram of the system is given in Figure 1.

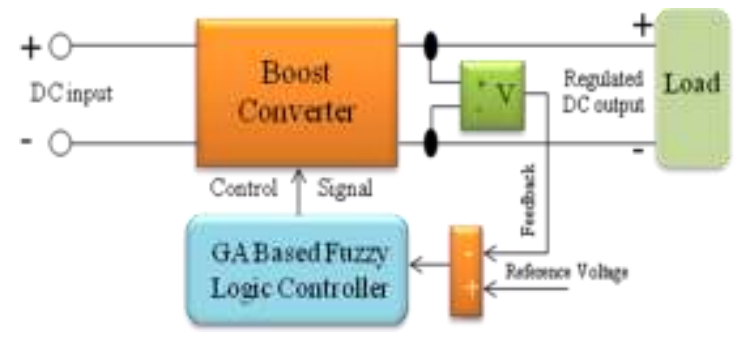

Figure 1. The general block diagram of the system

\section{RESEARCH SIGNIFICANCE}

In this study, a DC-DC boost converter has been designed in Matlab/Simulink environment. The system is performed under two conditions. The first one is that variable input voltage is fixed at a desired constant output voltage and the second one is that reference voltage tracking capability of the controllers is investigated. Proportional + Integral (PI) and Fuzzy Logic Controller (FLC) techniques are employed for the system control and the controller performances are compared with each other. Moreover, in order to improve the performance of the controllers, controller parameters are determined using the Genetic Algorithm (GA) with respect to integral of the time weighted absolute error (ITAE). Thus, a more efficient control is provided for the system.

\section{STRUCTURE OF STEP UP-TYPE DC-DC CONVERTER}

Step up-type DC-DC converter, which is a power electronics circuit, is used to enhance output voltage and the voltage is always equal and greater than the input voltage. The converter is preferred to produce a higher regulated output voltage from a lower irregular input voltage. In Figure 2, the power circuit belonging to an ideal overall structure of a step up-type DC-DC converter is being provided. The converter; consists of a semiconductor power switch $\mathrm{S}$, a diode D, an inductance $\mathrm{L}$, a filter capacitor $\mathrm{C}$ and $\mathrm{a}$ load resistance $\mathrm{R}$ [ 6 and 7].

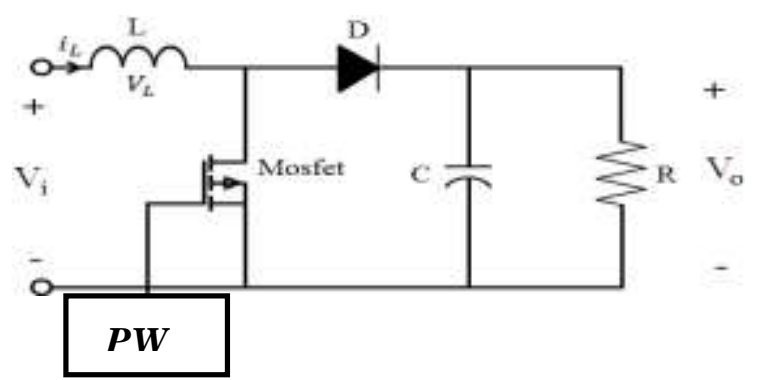

Figure 2. Overall structure of a step up type DC-DC converter

The system control is being performed by being shifted to transmission and cut off mode with the assistance of the pulse width modulation of semiconductor power switch in the circuit. When the semiconductor power switch shifted to ON position in the mode of continuous transmission, the diode is polarized inversely (OFF) and isolates the output circuit from the input. Meanwhile, the power supply feeds only the inductance and a constant current flows through hereof. As a result of this, the current passing through the coil increases and the energy begins to be stored on the coil. In this context, while DC power supply feeds the inductance, the capacitor 
feeds the load [4 and 8]. This event happened within $0<t \leq$ Td time interval is shown in Figure 3. When the semiconductor power switch is shifted to cut off mode, the diode gets polarized positively (ON) and the load is fed from both inductance and the DC power supply as well. As a result, an output voltage being higher than the input potential is obtained at the circuit. In addition, the power components are exposed the output voltage. In this case, the circuit is not operated being unloaded; otherwise the output voltage increases excessively and causes damage to the circuit. This event happening within $\mathrm{Td}<\mathrm{t} \leq \mathrm{T}$ time interval is shown in Figure 3 [8].

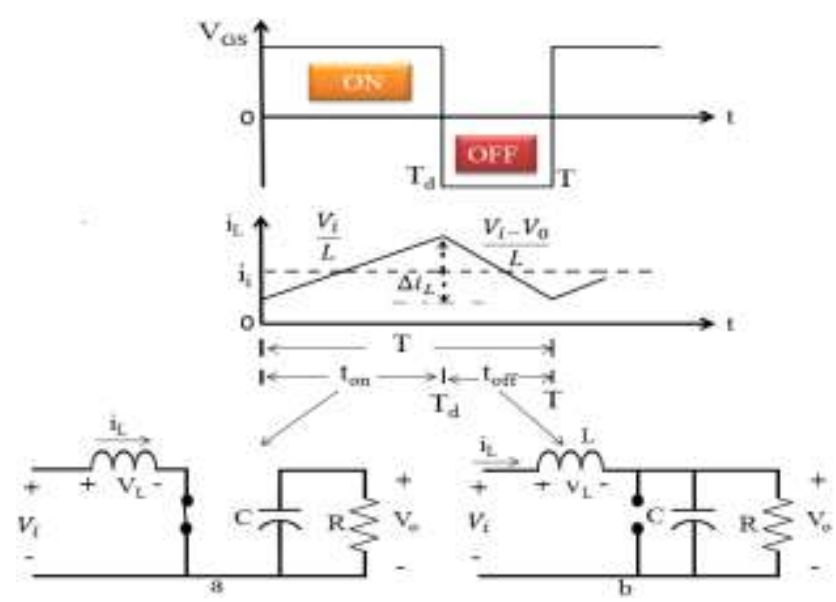

Figure 3. Continuous current transmission status a) Switch is in "ON" position b) Switch is in "OFF" position

As it would be seen from Figure 3, within the ton time interval, e.i. when the key is in ON position, the inductance voltage $V_{L}$ is equal to input voltage $V_{i}$. In the equation ( 1 and 2 ), the inductance voltage and inductance current iL expressions have been given.

$$
\begin{aligned}
& V_{L}=V_{i}=L \frac{d i_{L}}{d_{t}} \\
& i_{L}=\frac{1}{L} \int_{0}^{t} V_{i} d_{t}+i_{L 0}
\end{aligned}
$$

At the time interval $0<t \leq T d$, the inductance current increases due to $V_{i} / L$ expression in a linear gradient. At the $T d<t \leq T$ time interval, the inductance current decreases in the (Vi-V $\left.\mathrm{V}_{0}\right) / \mathrm{L}$ gradient. This situation is shown in Figure 3. $\Delta i_{L}$ represents the transformation of inductance current; its expression has been provided at equation (3) .

$$
\Delta i_{L}=\frac{V_{0} D(1-D)}{f_{s} L}
$$

Here, $f_{s}$ stands for the switching frequency, $D$ the occupancy rate, $\Delta i_{L}$ maximum value happens when occupancy rate becomes 0.5 . At the moment when it is $t=T d$, the switch shifts to OFF position and remains in this position throughout OFF period. When the switch shifts to OFF position, acting like a current source, the inductance receives the diode to transmission and the circuit at Figure 3(b) is obtained. This case in which the output voltage is greater than the source voltage $\left(V_{i}<V_{0}\right)$ shows the general characteristics of the DC-DC converters. Considering that net change of average inductance voltage or current is zero for one period at the DC-DC converters, the relationship 
between the input voltage and output voltage is achieved. This relationship is given at quotation (4) [5 and 8].

$$
\frac{V_{o}}{V_{i}}=\frac{1}{(1-D)}
$$

The value $D$ varies in the range of $0<D<1$. When the equation (4) is examined, the output voltage $\mathrm{D}=0$ takes its lowest at the state of $\mathrm{D}=0$ and becomes equal to input voltage. When the occupancy rate becomes $\mathrm{D}=1$, the output voltage becomes infinite and an undesired status appears. Therefore, maintenance applications occupancy rate is selected from the rage of $0.1<D<0.9$ in the applications. The minimum values of capacitor and inductance are calculated by using the formulas given in the equation (5) [9].

$$
C_{\min }=\frac{I_{\text {out }(\max )} D}{f_{s} \Delta V_{o}} \quad L_{\min }=\frac{V_{i}\left(V_{0}-V_{i}\right)}{\Delta i_{L} f_{s} V_{0}}
$$

\section{FUZZY LOGIC CONTROL}

The fuzzy logic concept, the foundations of which had been laid with the article [10] published by Lofti A. Zadeh in 1965 has been conceptualized on the uncertain values and has a new dimension [11] to be brought in the scrutiny of ambiguity-containing systems. Unlike the classical control systems, the fuzzy logic sets the mark applied to the system input so as provide only the wanted output without any need for the mathematical model of the system to the controlled. In this respect, the fuzzy control resembles to as if controlling that system by benefitting of a specialist person's knowledge and experiences. Moreover, being an approach having gone beyond the classic numeric (0.1) logic, the fuzzy logic as a result of generation of multi-level values between these two values, it ensures that the controller produces more accurate decisions which results in promotion of the performance and efficiency [12 and 14]. The basic components making up the fuzzy logic controller are shown in Figure 4.

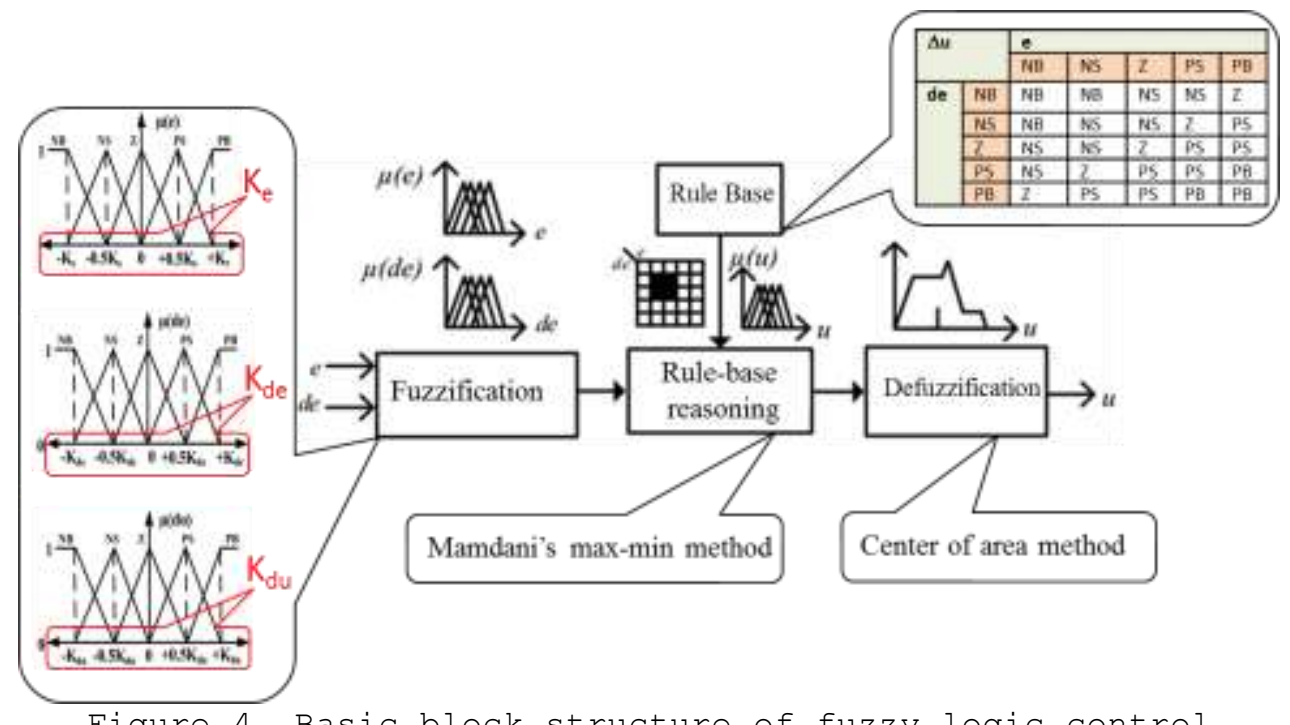

Figure 4. Basic block structure of fuzzy logic control

As it is shown in Figure 4, the fuzzy logic controller has two precise inputs, " $e$ " and "de" inputs. While "e" represents the error showing the difference between the reference and the output and "de" the change in the error. Membership functions in the fuzzy controller is a basic structure and they can be in various structures such as 
with a triangle, trapezoid, cauchy, sinusoid, Gaussian, sigmoid and bell. In this paper, the triangular membership function is employed [13 and 14]. The blurring unit being the first component of the fuzzy logic controller blurs the precise information coming to the controller input and ensures that they are expressed with membership values varying between 0 and 1. Upon acquisition of the blurred values which correspond to the precise inputs, they are sent to the inference rule based unit being the next step. Here, using the database and the linguistic control elements available in the rule base, the blurred results are acquired. By being sent to the defuzzification unit, these fuzzy interferences acquired are converted into precise numbers and thus the control signal required for the system to be checked becomes having been achieved [14]. The rule table composed of five memberships and twenty-five rules has been shown in Figure 4 and the linguistic labels employed have been expressed as negative big (NB), negative small (NS), zero (Z), positive big (PB) and positive small (PS). In this study, as a controller, proportional-integral (PI) controller and the fuzzy logic controller (FLC) from the conventional controllers have been used. The control structures used are shown in Figure 5 and Figure 6 .
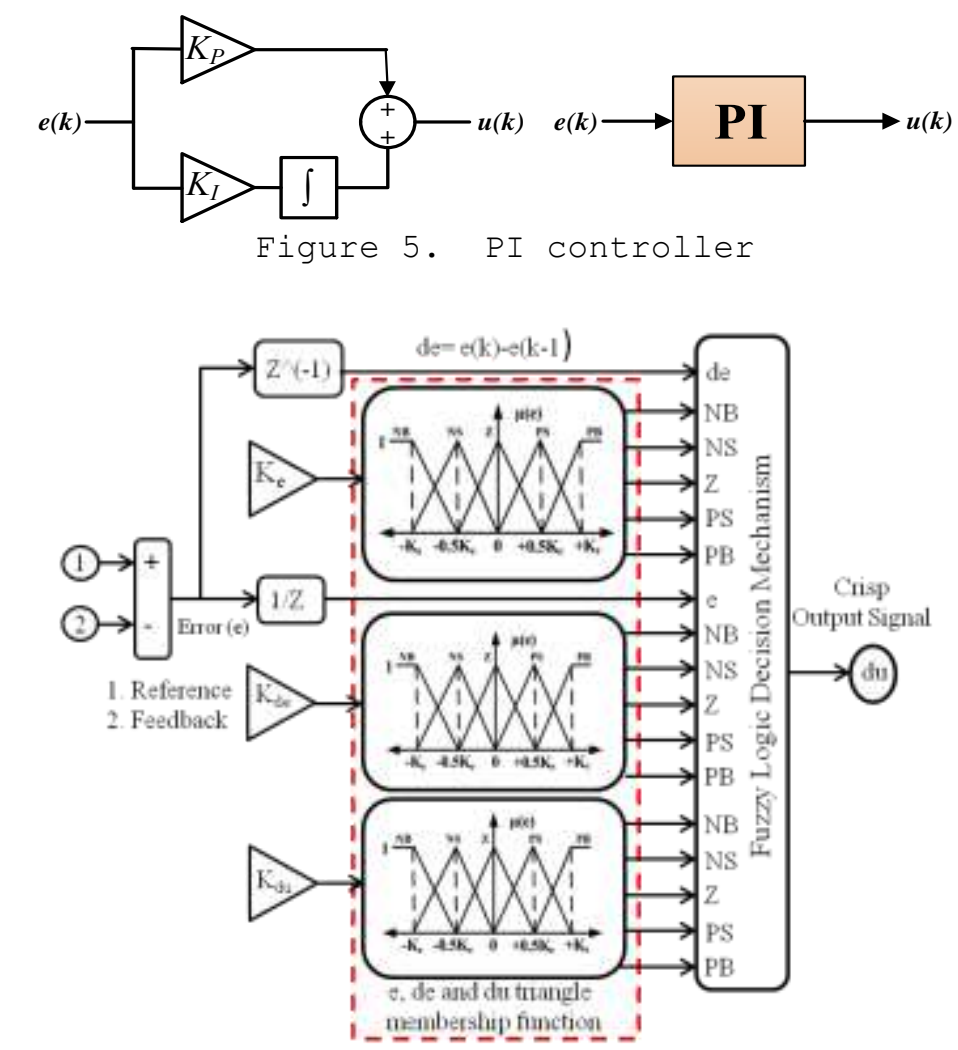

Figure 6. Matlab/Simulink block diagram of FLC

Here e, de and du means error, change of error and change of output signal, respectively. Some of the parameters to the controllers used in controlling the system have been determined by using the method of genetic algorithm (GA). Using GA, $K_{e}, K_{d e}, K_{d u}$ parameters have been optimized in fuzzy logic controller and KP and KI parameters in PI controller. So a more intelligent and efficient control has been provided for the system. The block diagram of the optimization process of FLC parameters is given in Figure 7 . 


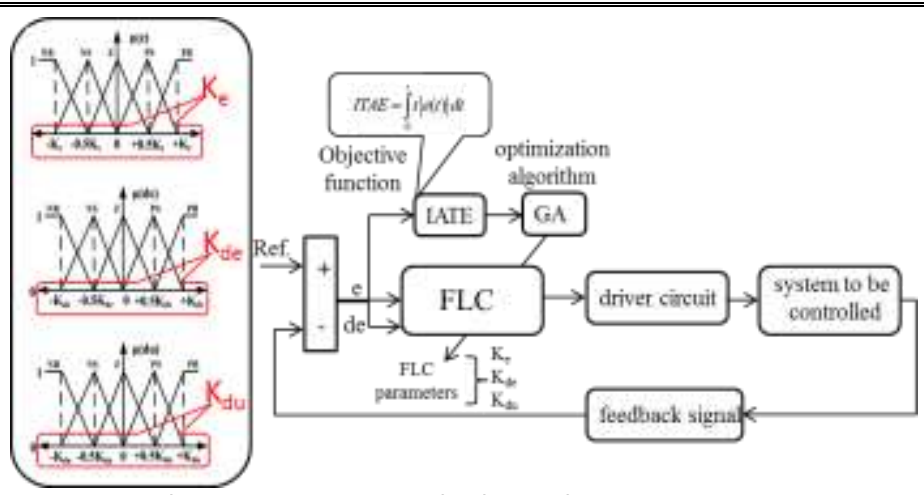

Figure 7. Block Diagram of Optimization Process of FLC Parameters

As the objective function in the system, integral of timeaggravated absolute error (ITAE) is utilized, and the mathematical expression of the objective function employed is given in the equation (6). In the equation used, " $r$ " is the reference, " $y$ " the system output and "e" error. In addition, the values obtained for ITAE value in consequence of 10 iterations using GA method for one controller is provided at Table 1 .

$$
\text { ITAE }=\int_{0}^{T} t|r(t)-y(t)| d t=\int_{0}^{T} t|e(t)| d t
$$

Table 1. Parameters determined with GA

\begin{tabular}{|c|c|c|c|c|}
\hline \multicolumn{2}{|c|}{ PI } & \multicolumn{3}{c|}{ BMD } \\
\hline KP & KI & $K_{e}$ & $K_{\text {de }}$ & $K_{\text {du }}$ \\
\hline 1.32 & 0.59 & 2.5 & 1.1 & 6.23 \\
\hline
\end{tabular}

\section{GENETIC ALGORITHM}

The genetic algorithm has been propounded by the psychologist and computer science specialist J.H. Holland from University of Michigan in 1975. The genetic algorithms are a post-application of the best protection method and natural selection principle occurred search method via simulation and it is used in solving the hard-to-analyze problems [15 and 16]. Since the genetic algorithms do not need any preliminary or derivative data for the problem solving process allowed this algorithm to be frequently employed in resolving the problems [16]. The most significant distinction of the genetic algorithm from other optimization methods and classical search methods is that it uses a set of solutions instead of a single solution [17].

The genetic algorithms reach at the most appropriate solution according to the survival principle of the best in the multidimensional spatial search. To reach at the most suitable outcome via this method in the spatial search, one set of solutions is composed instead of single solution and possibility of reaching an overall solution becomes having been improved. The set of solutions generated in the genetic algorithms are called to be population and the numeric sequences making up this population are called as chromosome or individual. Evolutionarily the individuals are determined by the operators and the projection of individuals in problem solving is a very important factor in GA. Whether or not the individuals represent the solution is determined by the conformity function and reproduction of individuals with higher conformity value actualized with other individuals within the population. Thus the spread of individuals possessing high conformity value is promoted within the population and this process is continuously repeated. Acquisition of the solution in 
the spatial search as a result of post-genetic processes combined other good features with the existing good features of these individuals is made easy [16 and 18]. Basically, the genetic algorithm consists of three main operators; reproduction, decussate and mutation. The flow chart of the genetic algorithm is given in Figure 8 .

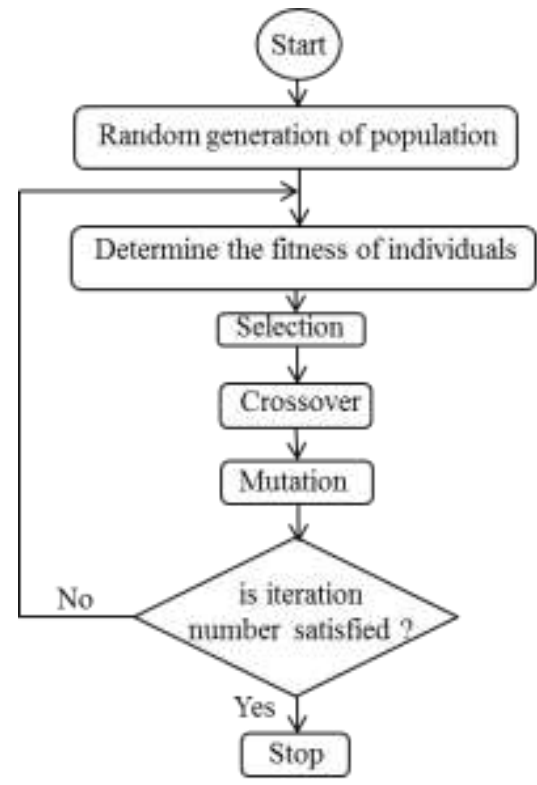

Figure 8. GA flow chart

\section{MATLAB/SIMULINK MODEL AND SIMULATION RESULTS OF SYSTEM}

The simulation chart generated in the block diagram of Matlab/Simulink for DC-DC converter is shown in Figure 9.

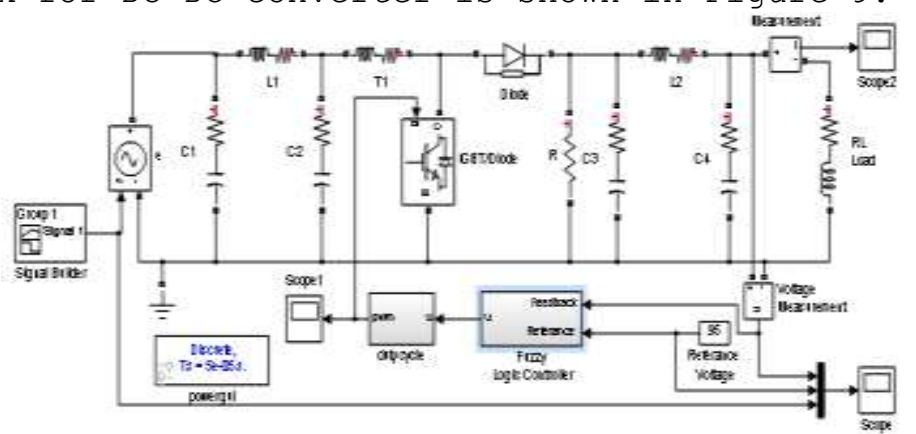

Figure 9. Matlab/Simulink Block Diagram Designed for DC-DC Converter

Simulation studies have been conducted with GA optimized parameters using Matlab/Simulink simulation program for different operating conditions. Under $\mathrm{R}$ and $\mathrm{RL}$ load conditions, the input voltage of DC-DC converter is variable and the output voltage is wanted to be fixed at 95 Volts. The simulation results related to the scenarios are shown in Figures 10 and 11. 

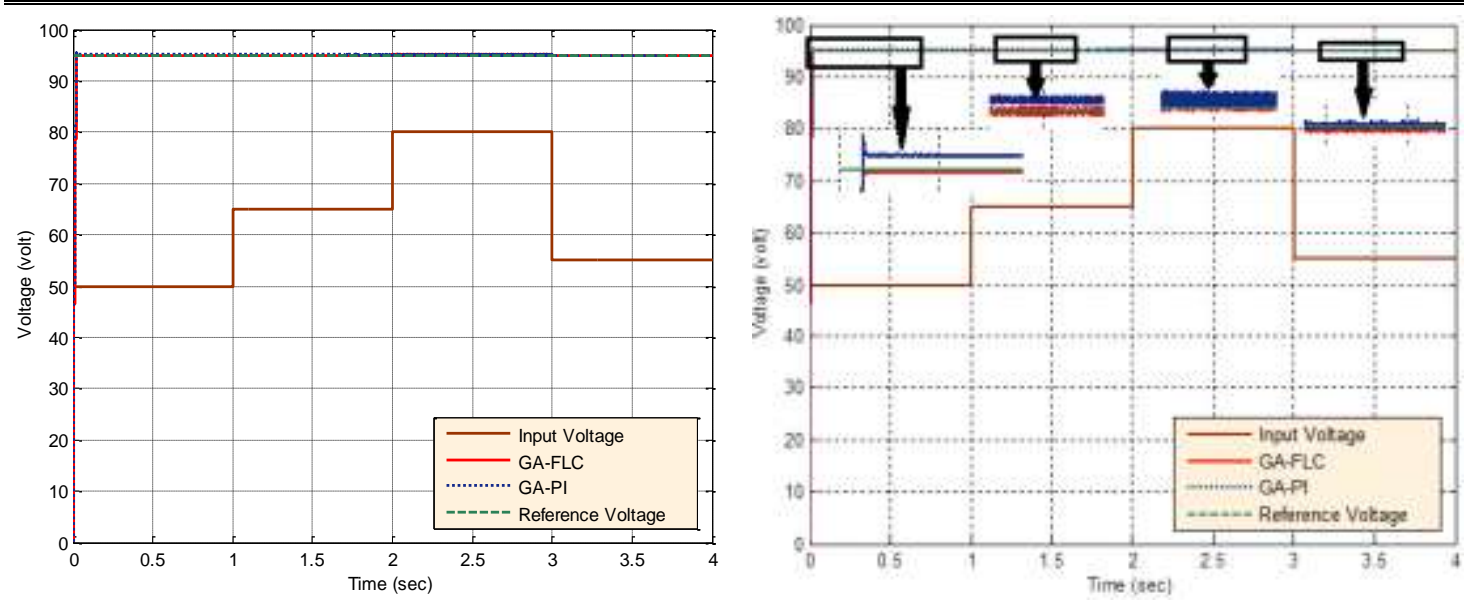

Figure 10. DC-DC Converter Output Voltage (Load R)
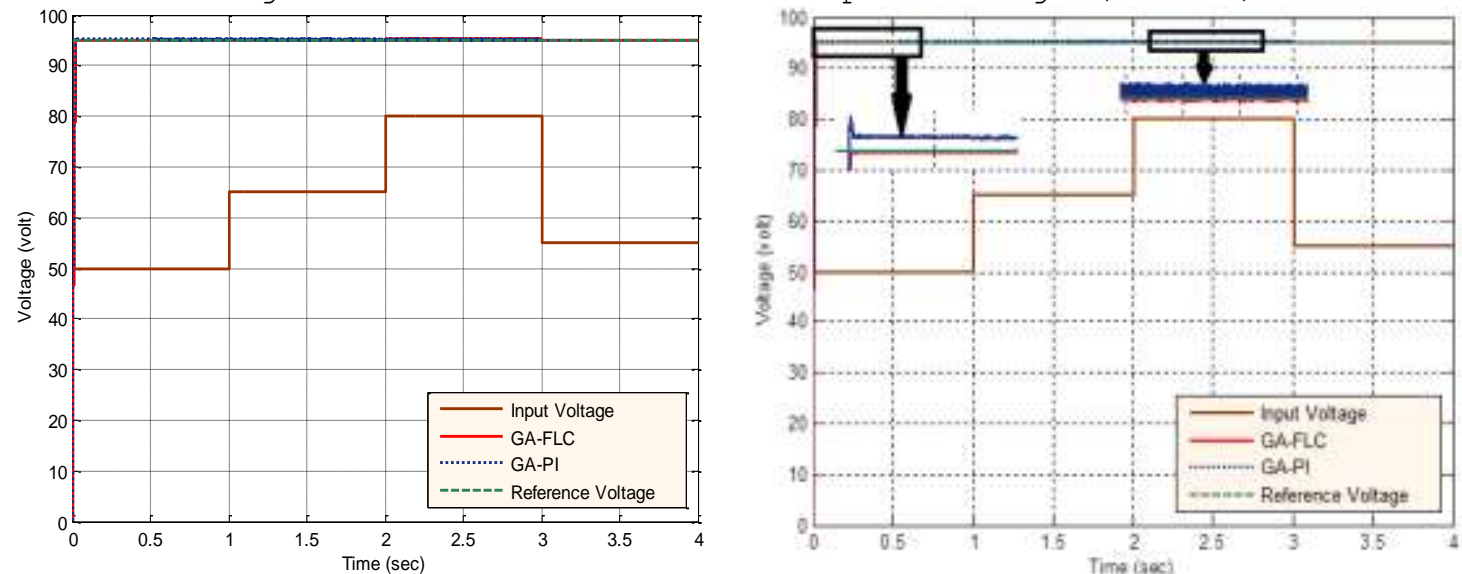

Figure 11. DC-DC converter output voltage (Load RL)

As shown in Figures 10 and 11, for the variable voltage input and constant output voltage of DC-DC converter in different load situations, PI controller has yielded worse result according to FLC in terms of steady state error overshoot and settling on the reference. The outcomes obtained for fixed input voltage and variable output voltage are shown in Figures 12 and 13.
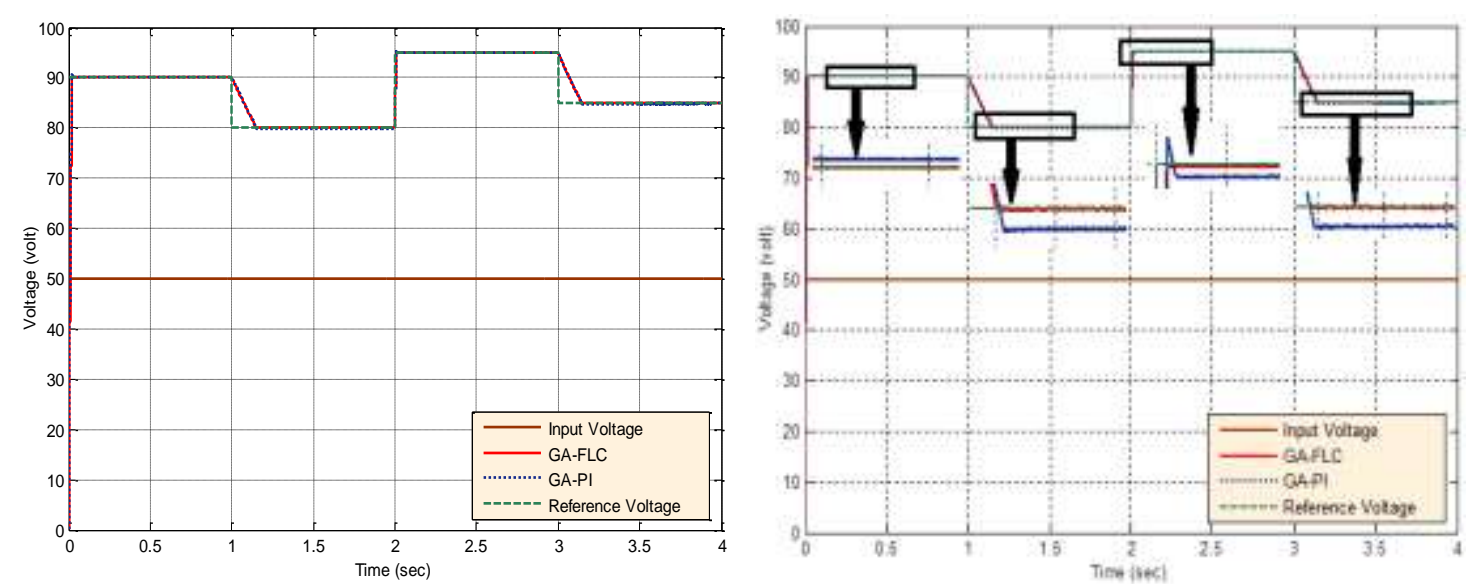

Figure 12. DC-DC converter output voltage (Load R) 

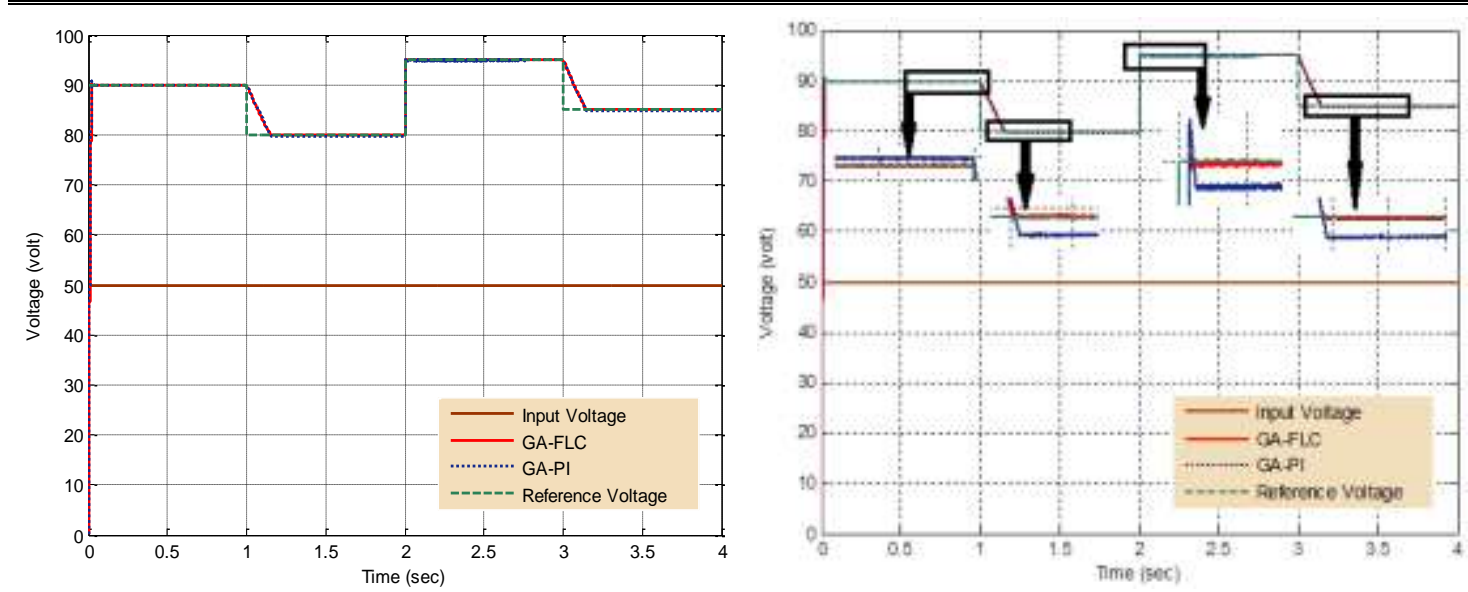

Figure 13. DC-DC converter output voltage (Load RL)

As it is shown in Figures 12 and 13, both controllers have followed the reference for the different load conditions in the mode of the constant input voltage and variable output voltage of DC-DC converter. However, FLC is provided better results in comparison to PI controller in terms of overshoot, settling on the reference and steady state error.

\section{CONCLUSIONS}

In this study, the control of a boost DC-DC converter has been realized with PI controller and FLC and the performance of controllers has been compared. In addition, some parameters determined with the aid of GA for the controllers used in the system have provided smarter and more efficient control. When the outcomes of the simulation were examined, it has been observed that FLC has provide better results under different load and operating conditions in terms of settling on the reference, steady state error in comparison to PI controller. Finally, it has been understood that both controllers have controlled the system in a stable manner, however, the PI controller has provided worse results versus FLC from the perspectives of steady state error, overshoot and settling time the reference.

\section{NOTICE}

This paper is an extended version of the paper which is published in International Conference on Advanced Engineering Technologies (ICADET), Bayburt, Turkey 2017.

\section{REFERENCES}

1. Vidal-Idiarte, E., Carrejo, C.E., Calvente, J., and MartinezSalamero, L., (2011). Two-loop Digital Sliding Mode Control of DC-DC Power Converters Based on Predictive Interpolation, IEEE Trans. Ind. Electro. , Vol:58, No:6, pp:2491-2501.

2. Oucheriah, Q. and Guo, L., (2013). The PWM-Based Adaptive Sliding-Mode Control for Boost DC-DC Converters, IEEE Transactions on Industrial Electronics, Vol:60, No:8, pp:32913294.

3. Bodur, H., (2012). Power Electronics 2. Edition, Istanbul: Birsen Publishing House

4. Assistant, O., (2008). Power Electronics 2. Edition, Istanbul: Birsen Publishing House

5. Sesli, E., (2012). Input Voltage and Variable Load DC/DC Step up Controller Control, Thesis, Trabzon: Black Sea Technical University, Institute of Science and Engineering. 
6. Elshaer, M. and Mohamed, A., (2010). Smart Optimal Control of DC-DC Boost Converter in PV Systems, Transmission and Distribution Conference and Exposition, pp:403-410.

7. Masri, Q. and Chan, P.W., (2010). Development of a Microcontroller-Based Boost Converter for Photovoltaic System, European Journal of Scientific Research, Vol:41 No:1, pp:38-47.

8. Akyazi, O., (2017). PSO-Based Fuzzy Logic Design Control for a DC/DC Boost Converter, Mugla Journal of Science and Technology, Vol:3, No:1, pp:58-63.

9. Sahin, E., Ayas, M.S., and Altas, I.H., (2014). A PSO-Optimized Fractional Order PID Controller for a PV System with DC-DC Boost Converter, $16^{\text {th }}$ International Power Electronics and Motion Control Conference and Exposition, pp:477-481.

10. Zadeh, L.A., (1965). Fuzzy Sets, Information and Control, Vol:8, $\mathrm{No}: 3, \mathrm{pp}: 338-353$.

11. Zadeh, L.A., (1973). Outline of a New Approach to the Analysis of Complex Systems and Decision Processes, IEEE Transactions on Systems Man and Cybernetics, Vol:3, No:1, pp:28-44.

12. Atlas, I.H. and Sharaf, A.M., (2007). A Photovoltaic Array Simulation Model for Matlab-Simulink GUI Environment, International Conference on Clean Electrical Power ICCEP, 07 , pp: $341-345$.

13. Akyazi, O., Usta, M.A., and Akpinar, A.S., (2012). A Self-Tuning Fuzzy logic Controller or Aircraft Roll Control System, International Journal of Control Science and Engineering, Vol:2, No:6, pp:181-188.

14. Okumus, H.I., Sahin, E., and Akyazi, O., (2013). Antenna Azimuth Position Control with Fuzzy Logic and Self-Tuning Fuzzy Logic Controllers, $8^{\text {th }}$ International Conference on Electrical and Electronics Engineering (ELECO), pp:477-481.

15. Nabiyev, V.V., (2005). Artificial Intelligence (ProblemsMethods-Algorithm), Ankara: Seckin Publishing.

16. Akyazi, O., (2016). GA-Based Optimal Fuzzy Logic Controller Design for DC/AC Converter Control, TOK 16 Automatic Control Turkish National Committee Automatic Control National Meeting, pp: $458-462$.

17. Karaoglan, O.G., (2007). For Systems with Fuzzy PID Controllers Using Genetic Algorithms-Assisted Regulation for Fuzzy PID Controllers of the Control Systems," Master Thesis", ITU Institute of Science.

18. Mitchell, M., (1998). An Introduction to Genetic Algorithms, MIT Press, Fifth Edition. 